\title{
Adoptive Immunotherapy Strategies with Cytokine-Induced Killer (CIK) Cells in the Treatment of Hematological Malignancies
}

\author{
Frederic Carsten Schmeel ${ }^{\dagger}$, Leonard Christopher Schmeel ${ }^{\dagger}$, Sanna-Marie Gast and \\ Ingo G. H. Schmidt-Wolf *
}

Medizinische Klinik und Poliklinik III, Center for Integrated Oncology (CIO), University Hospital Bonn, Rheinische Friedrich-Wilhelms-Universität Bonn, Sigmund-Freud-Straße 25, 53105 Bonn, Germany; E-Mails: cschmeel@uni-bonn.de (F.C.S.); schmeel@uni-bonn.de (L.C.S.); sun1979@hotmail.com (S.-M.G.)

$\dagger$ These authors contributed equally to this work.

* Author to whom correspondence should be addressed;

E-Mail: ingo.schmidt-wolf@ukb.uni-bonn.de;

Tel.: +49-228-287-17050; Fax: +49-228-287-9080059.

Received: 20 June 2014; in revised form: 14 July 2014 / Accepted: 11 August 2014 /

Published: 21 August 2014

\begin{abstract}
Cytokine-induced killer (CIK) cells are a heterogeneous population of immune effector cells that feature a mixed T- and Natural killer (NK) cell-like phenotype in their terminally-differentiated $\mathrm{CD}^{+} \mathrm{CD} 6^{+}$subset. The easy availability, high proliferation rate and widely major histocompatibility complex (MHC)-unrestricted antitumor activity of CIK cells contribute to their particularly advantageous profile, making them an attractive approach for adoptive immunotherapy. CIK cells have shown considerable cytotoxicity against both solid tumors and hematological malignancies in vitro and in animal studies. Recently, initial clinical experiences demonstrated the feasibility and efficacy of CIK cell immunotherapy in cancer patients, even at advanced disease stages. Likewise, the clinical application of CIK cells in combination with standard therapeutic procedures revealed synergistic antitumor effects. In this report, we will focus our consideration on CIK cells in the treatment of hematological malignancies. We will give insight into the latest advances and future perspectives and outline the most prominent results obtained in 17 clinical studies. Overall, CIK cells demonstrated a crucial impact on the treatment of patients with hematological malignancies, as evidenced by complete remissions, prolonged survival
\end{abstract}


durations and improved quality of life. However, up to now, the optimal application schedule eventually favoring their integration into clinical practice has still to be developed.

Keywords: CIK (cytokine-induced killer) cells; clinical trials; immunotherapy; cancer treatment

\section{Introduction}

Over the last few decades, considerable progress has been made in the treatment of hematologic malignancies. However, the long-term efficacy remains disappointing, since most patients might eventually relapse and suffer from severe side effects caused by chemotherapy and radiation. Especially in elderly patients, which are most susceptible for hematologic malignancies, treatment-related adverse events are a major cause of drug discontinuation and reduced dose-intensity, thus aggravating treatment efficacy [1]. Therefore, additional and better-tolerated therapeutic strategies must be sought.

In recent years, adoptive immunotherapy has emerged as an innovative strategy in cancer treatment and has increasingly attracted attention as an adjuvant or even as an alternative therapy option. It aims at stimulating the patients' immune system in order to trigger an antitumor immune response, eventually enabling the body's natural abilities to better recognize and, finally, kill cancer cells. Among various immunotherapeutic approaches, in particular the adoptive cellular immunotherapy using cytokine-induced killer (CIK) cells has turned out to be a promising pathway. The first studies in the literature already demonstrated the high cytotoxic potential of CIK cells against transformed hematopoietic cells in in vitro and animal tumor models [2,3]. Very recently, an increasing number of clinical trials have reported that the adoptive CIK cell transfer revealed considerable antitumor efficacy and led to both significantly improved progression-free and overall survival (OS) in patients bearing different, especially solid, types of cancer, while being without serious side effects and well tolerated by the patients. Moreover, CIK cell transfusions were shown to positively influence the quality of life (QOL) and immune parameters of cancer patients known to present with impaired immune functions at advanced disease stages [4-8].

CIK cells meet decisive requirements to be effective in an immunotherapeutic approach. These cytotoxic $\mathrm{CD}^{+}$T-cells, also known as natural killer (NK) cell-like T lymphocytes, expand more rapidly and exhibit a stronger anti-tumor activity than other reported immune effector cells [3,9]. They are generated by the sequential ex vivo incubation of human peripheral blood mononuclear cells (PBMC) with interferon-gamma (IFN- $\gamma$ ), anti-CD3 antibody and recombinant human interleukin (IL)-2 [2].

After this expansion procedure, two predominant subsets of either CD56-positive or CD56-negative CIK cells can be distinguished within the heterogeneous, mainly $\mathrm{CD}^{+} \mathrm{T}$-cell culture, whereby the exact proportions of either cell type may vary dependent on the application scheme used. Among them, the terminally-differentiated $\mathrm{CD} 3{ }^{+} \mathrm{CD} 56^{+}$subset represents the cell type with the highest tumor killing abilities. This subset acquired, as a key feature, a double T-cell and NK cell phenotype and, thus, exerts a potent and widely MHC-unrestricted anti-tumor cytotoxicity against a broad range of cancer cells $[3,10]$. Interestingly, these $\mathrm{CD}^{+} \mathrm{CD}^{+} 6^{+}$cells do not derive from NK cells, but develop 
from proliferating $\mathrm{CD}^{+}{ }^{+} \mathrm{CD} 56^{-} \mathrm{T}$-cells, which are still hampered by residual alloreactivity across Human Leukocyte Antigen (HLA) borders [3,11,12].

CIK cells' anti-tumor activity is perforin mediated and was mainly attributed to the cell-cell contact-dependent natural killer group 2 member D (NKG2D) cell-surface receptor, since antibody blocking experiments using anti-NKG2D antibody or siRNA showed that CIK cells mainly lost their T-cell receptor (TCR)-independent antitumor cytotoxicity against malignant cells. Most CIK cells express NKG2D, and its activity is associated with the adaptor molecule DNAX-activating protein of $10 \mathrm{kDa}$ (DAP10), which is, in turn, upregulated in CIK cells at high doses of IL-2 and not restricted to the $\mathrm{CD}^{+} \mathrm{CD}^{+} 6^{+}$fraction [13]. Both solid and hematologic tumor cells overexpress NKG2D ligands, typically MHC class I chain-related molecules (MIC) A/B and members of the UL16 binding proteins (ULBP) family, making them a favorable target of CIK cell-mediated cytolysis [14-16]. CIK cells also express some other activating NK receptors, like DNAM-1, NKp30, NKp44 and NKp46, which have been suggested to influence tumor recognition, as well; however, little is currently known about their involvement in the antitumor activity of CIK cells. Along with that, terminally-differentiated CIK cells are characterized by the expression of $\mathrm{CD} 45 \mathrm{RA}^{+}, \mathrm{CCr} 7^{-}, \mathrm{CD} 11 \mathrm{a}^{+} \mathrm{CD}_{2} 2 \mathrm{~L}^{-/+}, \mathrm{CD} 27^{+}$and $\mathrm{CD} 28^{-}$with more late effector features present in the $\mathrm{CD}^{+} \mathrm{CD}^{+} 6^{+}$subset than in $\mathrm{CD}^{-} 6^{-}$cells $[11,17]$.

Many adoptive immunotherapies using various killer cells, i.e., standard lymphokine-activated killer (LAK) cells and tumor-infiltrating lymphocytes (TILs), have merely shown limited efficacy in clinical trials, due to their poor expansion ability and low antitumor activity [18]. Particularly, LAK cells, after expansion from peripheral PBMCs at high doses of IL-2, revealed an MHC-unrestricted cytotoxicity against tumor cells, as CIK cells do. In comparison, however, CIK cells can be obtained more efficiently and turned out to be more specific in the killing of tumor cells [9]. Thus, CIK cells, due to their advantageous cytotoxic profile and recent clinical results, might have the potential to substantially enhance future cancer immunotherapy. This is why it took no long for numerous clinical studies to investigate CIK cells' efficacy towards a broad scope of neoplasms. In this report, we will give insight into the efficacy of CIK cells with a focus on hematological malignancies. Therefore, we will summarize the latest advances in CIK cell immunotherapy and outline the most prominent results obtained in clinical studies that utilized CIK cells for the therapy of hematological neoplasms.

\section{Improving CIK (Cytokine-Induced Killer) Cell Proliferation and Efficacy}

In 1991, Schmidt-Wolf et al. [2] developed a standard protocol for the generation and expansion of CIK cells, which our workgroup still uses until today. Accordingly, CIK cells can be generated in vitro by the addition of IL-2 to PBMCs. Nevertheless, by now, CIK cell cultivation conditions have been extensively modified, and much research is ongoing to improve both the propagation and tumor-specific cytotoxicity. Particularly, the use of cytokines other than IL-2 has been addressed so far. A further special focus was put on the suppression of T-regulatory cells (Tregs) within the CIK cell culture, since their removal led to enhanced cytotoxicity [19].

Lin et al. [20] found out that the use of IL-6 every two to three days led to the increased proliferation rate and cytotoxic activity of CIK cells. This was broadly in line with the observation that the proportion of the desired $\mathrm{CD} 3{ }^{+} \mathrm{CD} 56^{+}$effector cells was significantly increased, eventually resulting in a higher in vitro cytotoxicity. Simultaneously, the proportion of Tregs within the CIK cell 
culture was also significantly decreased, suggesting that IL-6 might additionally inhibit the immunosuppressive functions of Tregs.

Recently, Heninger et al. [21] reported on similar results showing that the cultivation with IL-7 also leads to a higher proliferation rate and cytotoxicity as compared to solely IL-2 expanded CIK cells. Interestingly, this observation was accompanied by a highly abrogated immunosuppressive Tregs function. IL-7 gene-transfected CIK cells provided these beneficial features as well [22].

With particular regard to hematological malignancies, likewise, the alternative use of IL-15 instead of IL-2 revealed considerable advantages. CIK cells stimulated by IL-15 exhibited an enhanced cytotoxic activity against acute lymphoblastic leukemia and lymphoma cell lines, as well as against primary acute myeloid and defined lymphoblastic leukemia cells [23]. Additionally, the percentages of $\mathrm{CD}^{+}{ }^{+} \mathrm{CD} 56^{+}$cells significantly increased, while the immunosuppressive functions of Tregs and IL-35 were also depressed [24].

Furthermore, the cultivation with IL-21 was shown to increase the expression of IL-21 receptors, perforin, granzyme B, Fas ligand, IFN- $\gamma$ and tumor necrosis factor- $\alpha$. Besides that, the relative proportions of the desired $\mathrm{CD}^{+} \mathrm{CD} 6^{+}$cell population increased, but without enhancing the general proliferation rate [25]. Based on these qualities, IL-21 might become another interesting candidate for future CIK cell cultivation.

Finally, there is growing evidence that co-cultivation with dendritic cells (DC) could additionally improve the anti-tumor toxicity and reduce the number of Tregs within the CIK cell culture. Moreover, the combined cultivation (DC-CIK) was capable of improving the expansion and frequency of $\mathrm{CD}^{+}{ }^{+} \mathrm{CD} 56^{+}$cells in the amplified population, while the interactions between DCs and CIK cells led to an increase of the IL-12 secretion [26-30].

\section{Alloreactivity}

Within the framework of hematological malignancies, CIK cells' alloreactivity is of major importance, since allogeneic hematopoietic stem cell transplantation (HSCT) often remains as the only curative therapeutic option for many patients affected by hematologic neoplasms. A major benefit of allogeneic HSCT in the treatment is the graft-versus-tumor (GVT) effect conferred by lymphocytes contained within the graft. This GVT effect can even be utilized as a therapeutic means after the relapse of disease by the infusion of donor lymphocytes (donor lymphocyte infusion (DLI)). However, these lymphocytes can also be responsible for the potentially severe complication of graft-versus-host disease (GVHD). Importantly, in this respect, CIK cells displayed reduced alloreactivity across HLA barriers. In a murine model, CIK cells exhibited strong in vivo antitumor toxicity by GVT activity with minimal to no GVHD after transplantation across MHC barriers into tumor-bearing hosts [31]. Another murine model of the same group revealed the association of high IFN-gamma levels produced by CIK cells with the reduction of GVH activity; cells expanded from IFN-gamma knock-out animals caused GVHD [32].

Most interestingly, two distinct subsets of CIK cells were shown to be responsible for either alloreactivity or anti-tumor activity. Antitumor efficiency was mainly caused by $\mathrm{CD} 3^{+} \mathrm{CD} 56^{+}$cells, whereas alloreactivity was restricted to the $\mathrm{CD} 3{ }^{+} \mathrm{CD} 56^{-}$fraction. This might indicate that a depletion 
of $\mathrm{CD}^{+} \mathrm{CD}^{-} 6^{-}$cells can result in a reduced risk of GVHD without alleviated tumor-killing capacity and, thereby, opens up safer treatment modalities with CIK cells, even across major HLA barriers [12].

\section{Phase I Clinical Studies on Autologous CIK Cells}

The very first clinical report on the administration of CIK cells for the treatment of various malignancies was performed by Schmidt-Wolf et al., 1999 [10]. Here, a 54 year-old man, suffering from follicular lymphoma grade I, received a total of $1.84 \times 10^{9}$ autologous CIK cells in two cycles. There was no treatment toxicity, and a pre-existing bone marrow involvement as the only sign of disease resolved after CIK cell therapy. This was scored as a complete clinical remission (CR). Along with this clinically-improved presentation, the patient was shown to have increased serum levels of IFN- $\gamma$ and transforming growth factor beta (TGF- $\beta$ ) after CIK cell treatment. Leemhuis et al. [33] subsequently reported on a phase I study for the treatment of relapsed lymphomas after autologous stem cell transplantation (HSCT). Therefore, they enrolled nine patients with an age range from 23 to 67 years. Seven patients presented with advanced Hodgkin's disease (HD) and two patients with B-cell non-Hodgkin's lymphoma (NHL). A total of 21 infusions were given to nine patients. The number of CIK cells infused ranged from $1.0 \times 10^{9}$ to $1.0 \times 10^{10}$ per treatment. The toxicity was minimal, and there were no immediate side effects to the infusions. Three patients with HD and one patient with NHL responded to the therapy. Two patients with HD achieved partial remissions (PR), and two patients had stabilization of disease (SD); one for more than 18 months [33].

Besides patients bearing solid tumors, Olioso et al. [34] enrolled six patients suffering from advanced lymphomas (three HD) in a pilot phase I trial. The median number of transferred cells per patient was $7 \times 10^{9}$ (range 2.2-21). CIK cells were administered every three weeks three times. Merely one patient with centroblastic-centrocytic NHL achieved and sustained CR, even after 44 months of follow up. The remaining patients did not clinically respond to CIK cells at all. Only mild fever was observed in the patients collectively. Interestingly, immunological effects, such as significantly increased levels of IFN- $\gamma$ and TNF- $\alpha$, were solely found in responding patients. In contrast, non-responding patients showed no significant alterations in cytokine levels [34].

Yang et al. [35] infused 2-3 × 109 autologous CIK cells into nine elderly patients with B-cell NHL, followed by subcutaneous injection of IL-2 at a single daily dose of $1 \times 10^{4} \mathrm{U} /$ day for 10 consecutive days. In seven and two patients, eight and four of these cycles were completed, respectively. The corresponding CIK cell treatment cycles were repeated every four weeks. All nine patients did not develop any adverse reactions. On the contrary, lymphoma symptoms relieved, and the quality of life was obviously improved. Additionally, the relative numbers of $\mathrm{CD}^{+}, \mathrm{CD}^{+} \mathrm{CD}^{+}$and $\mathrm{CD} 3{ }^{+} \mathrm{CD} 56^{+}$ T-cells increased significantly, and unspecific tumor marker levels, like $\beta 2$-microglobulin and lactate dehydrogenase (LDH), decreased. Overall, the results were promising, since eight of nine patients achieved CR [35].

The same treatment procedure and schedule was applied by Liu et al. [36] to evaluate the effectiveness of CIK cell treatment combined with IL-2 in the treatment of six geriatric patients with myelodysplastic syndrome (MDS). Again, no severe adverse effects occurred. Along with CIK cell treatment, inflammation frequency and high fever durations were significantly reduced. Likewise, as stated by the authors, a reduction in blood transfusions required to stabilize hemoglobin levels 
could be observed during the stable stage of disease. In this context, patients did not receive erythropoietin-stimulating agents. Again, the percentages of $\mathrm{CD}^{+}, \mathrm{CD}^{+} \mathrm{CD}^{+}$and $\mathrm{CD} 3{ }^{+} \mathrm{CD} 56^{+}$ T-cells increased significantly, and patients experienced an improved QOL; however, transformation from myelodysplastic syndrome to high-risk subtypes could not be interrupted [36].

As the next step, Yang et al. [37] enrolled 20 patients in a phase I trial. The patients' age ranged from 57-93 years with a median age of 83 years. Among them, nine were diagnosed with lymphoma, five with MDS, two with multiple myeloma (MM), three with chronic lymphocytic leukemia (CLL) and one with acute myeloid leukemia (AML). Once more, Yang et al. [37] combined the CIK cell infusions $\left(2-3 \times 10^{9}\right)$ with subcutaneous injections of IL-2 (1 mU/day) for 10 consecutive days after each infusion. Six patients received four cycles, and the remaining 14 were administered eight cycles. Three patients developed malaise and low-grade fever, which disappeared after symptomatic treatment. Positive immunologic effects were observed as evidenced by an increased number of $\mathrm{CD}^{+}$, $\mathrm{CD}^{+}{ }^{+} \mathrm{CD} 8^{+}$and $\mathrm{CD}^{+}{ }^{+} \mathrm{CD} 56^{+}$cells. Moreover, the levels of serum $\beta 2$ microglobulin and $\mathrm{LDH}$ were markedly decreased. After follow up, CR, PR and SD were observed in eleven, seven and two patients, respectively. In detail, five of nine lymphoma patients experienced an improved clinical state with even three patients improving from progressive disease to $\mathrm{CR}$, while four patients could maintain their previous disease state as determined prior to CIK cell treatment; the disease state of all remaining eleven patients improved, with nine of them even achieving CR or PR. Additionally, the QOL markedly improved as demonstrated by an increased Karnofsky score from 57\% (40\%-90\%) to $83 \%$ $(60 \%-100 \%)$ [37]. Subsequently the same group reported on nine geriatric patients (aged from 65-90 years) with diffuse large B-cell lymphoma, which were pretreated with four courses of R-CHOP (Rituximab, Cyclophosphamide, Doxorubicin Hydrochloride (Hydroxydaunomycin), Vincristine Sulfate (Oncovin) and Prednisone) before CIK cell treatment. After pretreatment, seven patients achieved PR, and two achieved CR. The patients received eight cycles, as described in the workgroup's previous study. A total of $5 \times 10^{9}-1 \times 10^{10} \mathrm{CIK}$ cells were given per infusion. Two patients developed mild fatigue and low-grade fever. At the study endpoint, CRs were observed in all patients, and lymphoma-related symptoms were markedly improved with a survival time of 24-35 months. Again, increased proportions of $\mathrm{CD}^{+}, \mathrm{CD}^{+} \mathrm{CD}^{+}$and $\mathrm{CD}^{+} \mathrm{CD} 56^{+}$cells were observed [38].

By applying almost the same therapy protocol, the workgroup then assessed the efficiency of CIK cells towards B-cell CLL. This time, opposite to their prior trials, thymic peptide $\alpha 1$, used for treating diseases associated with immune dysfunction, including viral infections, such as hepatitis B and C, was given subcutaneously as an immunoenhancement at a dose of $1.6 \mathrm{mg} /$ day for 14 days before and after CIK cell administration. Forty six cycles of CIK cell infusions (each (4-6) $\times 10^{9}$ CIK cells) plus IL-2 were completed in five CLL patients. Besides the interesting observation that the CIK cell amplification time, the cell amount and antitumor cytotoxicity was significantly increased after thymic peptide $\alpha 1$ treatment, patients' clinical state improved as evidenced by transformation from PR to CR in three patients, from SD to $\mathrm{PR}$ in one patient and from progression of disease to $\mathrm{SD}$ in one patient [39].

Very recently, the group of Yang et al. [40] reported on a 68 year-old man with advanced refractory multiple solitary plasmacytomas and multiple bone lesions. CIK cells were infused once a month 
$\left(2-8 \times 10^{9}\right.$ cells), and 21 courses of CIK cell treatment had been administered. All bone lesions were relieved and the patient achieved CR, lasting till the end of follow-up [40].

Merely one phase I study reported on the non-superior anti-tumor efficiency of autologous CIK cell therapy. In five elderly patients with acute myeloid leukemia (AML), no instances of side effects were observed, and immunotherapy could significantly reduce both the incidence of infections and high fever durations. Without improving the clinical disease state, but worthy of being mentioned, CIK cell treatment could significantly reduce the volume of erythrocyte infusions required to maintain hemoglobin levels as compared with the patients' previous transfusion needs. However, even if CIK cell treatment could control the patients' general condition, the outcome of AML could not be changed [41].

\section{Phase I Clinical Studies on Allogeneic CIK Cells}

The first promising results obtained by the utilization of CIK cells in patients that had relapsed after allogeneic HSCT were reported by Introna et al., 2007 [42]. They enrolled eleven patients with a median age of 53 (range 24-62), of whom four presented with AML, three with HD, one with pre-B acute lymphoblastic leukemia (pre-B ALL), one with chronic myelomonocytic leukemia (CMML) and two with MDS. Six and five of them had undergone sibling or unrelated donor HSCT, respectively. With the exception of two patients, they were pretreated with reduced intensity protocols prior to HSCT. After a median time of 315 days from transplantation, patients were given between one to seven infusions (median 2) at three to four week intervals with a median number of $12.4 \times 10^{6}$ $\left(7.2-87.4 \times 10^{6}\right)$ CIK cells. Despite the information that all transfusions were well tolerated, as there were no immediate or late adverse reactions, four patients developed acute graft-versus-host disease (GVHD) within 30 days after the last infusion. Two of them progressed into extensive chronic GVHD (grade II). However, these GVHD cases only occurred in patients that received donor lymphocyte infusions (DLI) before the treatment with CIK cells. Consequently, this might hamper certain conclusions on the induction of GVHD by allogeneic CIK cells. Six patients did not benefit from CIK cells and eventually died. It is, however, noteworthy that one patient experienced SD, one PR and three even achieved CR [42].

In 2012, Laport et al. [43] reported on a comparable approach with 18 patients who relapsed after allogeneic HSCT using a matched sibling donor. The enrolled patients collectively had a median age of 53 years and consisted of patients with the following diagnoses: NHL $(n=5)$, AML $(n=3)$, MM $(n=3)$, CLL $(n=2)$, ALL $(n=2)$, MDS $(n=2)$ and HD $(n=1)$. Twelve of them had received a reduced intensity conditioning regimen, and six had received myeloablative regimens. All but two patients were treated with cytoreductive therapy, including chemotherapy, corticosteroids, surgical resection or DLI, before receiving CIK cells. After a median time of four months (range 1-34 months) from relapse to infusion, patients were given merely one infusion of CIK cells at escalating doses of $1 \times 10^{7}(n=4), 5 \times 10^{7}(n=6)$ and $1 \times 10^{8}(n=8)$ cells/kg. Acute GVHD, grades I-II, and limited chronic GVHD were developed by two and one patient, respectively. The median overall survival was 28 months and the median event-free survival was four months. Eight patients died due to relapsed disease within the follow-up duration of 1-69 (median 20) months [43]. However, longer remissions 
were seen in five patients after CIK cell administration compared to remission durations from allogeneic transplantation to relapse.

In another study, the feasibility and toxicity of cord blood-derived CIK cells were under investigation. Therefore, five patients with relapsed acute leukemia after cord blood transplantation were treated with HLA-matched cord blood-derived CIK cells. No acute or delayed adverse events were observed. A partial response concomitantly with the development of acute grade III GVHD was seen in one patient [44].

Linn et al. [45] provided some interesting results suggesting the efficiency of allogeneic CIK cells in patients that did not respond to various individualized chemotherapy regimens and donor lymphocyte infusion (DLI). Allogeneic CIK cells were successfully generated for a total of 24 patients, of whom, eight were diagnosed with AML, three with ALL, three with HD, one with CML and one with NHL. A total of 55 infusions were done for 16 patients with doses ranging from ten to 200 million $\mathrm{CD}^{+}$cells $/ \mathrm{kg}$; prior to the infusions, eight patients were excluded from the study. Acute GVHD occurred in three, but discontinued after treatment. For six patients, CIK cell therapy was not beneficial. The response of five patients was not assessed due to concomitant use of other agents that might have influenced the observed clinical result. Eventually, it was stated that the results of two ALL, two HD and one AML patient were suggestive of the clinical efficacy of CIK cells [45].

\section{Phase I/II Clinical Studies on Autologous CIK Cells}

Jiang et al. [46] evaluated the efficacy of CIK cell therapy followed by chemotherapy in 41 patients with acute leukemia. Nineteen patients received CIK cell treatment prior to chemotherapy, and 22 patients received chemotherapy only, thereby constituting the control group. The programs of chemotherapy in the two groups were similar. In the immunotherapy group, eight patients received four courses, two patients three courses, five patients two courses and four patients merely one course of CIK cell treatment. The amount of transfused CIK cells per patient were $(14.2 \pm 8.5) \times 10^{9} / \mathrm{L}$. All patients achieved and maintained CR for more than six months after chemotherapy. After for years of follow up, the continuous CR rate was $73.4 \%$ in the CIK group vs. $27.3 \%$ in the control. Thus, the CR rate was significantly higher in patients receiving CIK cells before chemotherapy than in patients who received chemotherapy only. Moreover, the efficacy of $\geq 3$ courses was better than in patients who received $<3$ courses of treatment. CRs lasted until the end of follow-up in the combination group. However, four of nine patients who received $<3$ courses of CIK cell treatment relapsed after CR during the follow-up duration [46].

During another study, thirteen AML patients in remission after autologous HSCT and eleven patients with CML on imatinib with residual disease detectable by polymerase chain reaction (PCR) received CIK infusions at three weekly intervals. Out of thirteen AML patients and ten CML patients, eleven and ten successfully generated autologous CIK cells, respectively. Three, one, five and two AML patients were given one, two, three and four infusions, respectively. These infusions were administered after a median time of 16 days post-transplant (range 13-37 days) when patients had recovered from cytopenia after HSCT. In the CML group, all patients received four infusions. Each infusion contained a median cell dose of $12.72 \times 10^{9}\left(1.3-78.6 \times 10^{9}\right)$ cells for the AML group and $25.72 \times 10^{9}\left(13.76-54.94 \times 10^{9}\right)$ cells for the CML group. Fever occurred as the only side effect and 
was easily controllable. At the end, no clinical benefit was observed in the AML group, as the relapse-free survival time was not significantly different compared to historical controls. Likewise, no benefit was seen in the CML group [47].

The only clinical study that combined CIK cells with dendritic cells (DC) for the treatment of multiple myeloma was reported by Zhong et al., 2012 [48]. Sixty patients were randomly divided into two groups. One patient group built the control group and received chemotherapy only; the second group was treated with chemotherapy plus DC-CIK. DCs were cultured in vitro by treating PBMCs with granulocyte-macrophage colony-stimulating factor (GM-CSF) and IL-4 and subsequently pulsed with MM cell lysate. Both CIK cells and DCs were adoptively transferred with $2.5-5 \times 10^{9}$ cells per transfusion. After immunotherapy, the percentages of CD3, CD8 and CD56 cells were significantly increased. In addition, the levels of $\mathrm{HSP} 70$ and the Th1/Th2 ratio were higher, while the proportions of anti-inflammatory TGF-beta, $\beta 2$-microglobulin and $\mathrm{CD} 4{ }^{+} \mathrm{CD} 25^{+}$regulatory $\mathrm{T}$-cells decreased. At the study endpoint, OS was significantly improved, with 42.9 vs. 33.6 months in the immunotherapy and chemotherapy group, respectively. Moreover, the QOL and clinical indices in the joint group were significantly better than in the chemotherapy group [48].

\section{Overall Benefits and Toxicity}

Taken together, 206 patients with an age ranging from 18-93 years (median $53 \pm 17.76$ ) were enrolled in 17 clinical studies. They received between one and 21 infusions with a mean and median number of 5.5 and 3.5 infusions, respectively. The CIK cell dose for each infusion ranged from $1 \times 10^{8}-2.8 \times 10^{10}$ with a median number of $5 \times 10^{9} \mathrm{CIK}$ cells. Side effects were mostly minor, as shown in Table 1 . However, mild fever $\left(37.5-40{ }^{\circ} \mathrm{C}\right)$ often occurred after CIK cell infusions, but lasted only up to $24 \mathrm{~h}$ after each infusion and was easily treatable with symptomatic means, like non-steroidal antiphlogistic medication. In a single study, two patients developed transient ventricular arrhythmias. However, the etiology of the arrhythmias and a possible association with CIK cell therapy was never elucidated.

Table 1. Side reactions associated with CIK cell therapy. GVHD, graft-versus-host disease; CIK, cytokine-induced killer.

\begin{tabular}{cc}
\hline Side Reaction & Frequency in \% \\
\hline Fever $\left(37.5-40{ }^{\circ} \mathrm{C}\right)$ & 26.37 \\
GVHD (grade I-II) & 14 \\
Ventricular arrhythmia & 1 \\
Chills & 1 \\
Fatigue & 1 \\
\hline
\end{tabular}

Side reactions following CIK cell immunotherapy in 206 patients.

CRs and PRs were observed in many patients that had undergone CIK cell therapy. Table 2 briefly summarizes the respective results and gives an overview on the described clinical trials. 
Table 2. Clinical studies using CIK cells.

\begin{tabular}{|c|c|c|c|c|c|}
\hline Study Reference & Phase & Cancer Disease & Patients $(n)$ & Therapy & Clinical Response \\
\hline Schmidt-Wolf et al. [10] & I & $\begin{array}{l}\text { Colon carcinoma (7) } \\
\text { follicular lymphoma (2) } \\
\text { Renal cell carcinoma (1) }\end{array}$ & 10 & $\begin{array}{l}\text { IL-2-gene transfected, } \\
\text { autologous CIK cells }\end{array}$ & $\begin{array}{l}\mathrm{CR}(1), \mathrm{SD}(3) \text {; } \\
\text { CIK cell therapy led to CR in one patient with } \\
\text { follicular lymphoma }\end{array}$ \\
\hline Leemhuis et al. [33] & I & $\begin{array}{c}\text { HD (7) } \\
\text { B-cell NHL (2) }\end{array}$ & 9 & autologous CIK cells & $\mathrm{PR}(2), \mathrm{SD}(2)$ \\
\hline Olioso et al. [34] & I & $\begin{array}{c}\text { HD (2) } \\
\text { B-cell NHL (4) } \\
\text { Renal cell carcinoma (5) } \\
\text { Hepatocellular carcinoma (1) }\end{array}$ & 12 & autologous CIK cells & $\begin{array}{l}\text { CR (3), PR (1), SD (2); } \\
\text { one patient with B-cell NHL achieved PR; enhancement of } \\
\text { immune functions, significantly prolonged OS in } \\
\text { clinical responders }\end{array}$ \\
\hline Yang et al. [35] & I & B-cell NHL & 9 & autologous CIK cells + IL-2 & $\begin{array}{l}\text { CR (8), PR (1); } \\
\text { enhancement of immune functions, improved quality of life }\end{array}$ \\
\hline Liu et al. [36] & I & MDS & 6 & autologous CIK cells + IL-2 & $\begin{array}{l}\text { Transformation from MDS to high-risk subtypes could not } \\
\text { be changed by CIK cell treatment, but inflammation } \\
\text { frequency was significantly reduced }\end{array}$ \\
\hline Yang et al. [37] & I & $\begin{array}{c}\text { HD (1) } \\
\text { B-cell NHL (8) } \\
\text { MDS (5) } \\
\text { MM (2) } \\
\text { CLL (3) } \\
\text { AML (1) }\end{array}$ & 20 & autologous CIK cells + IL-2 & $\begin{array}{l}\text { CR (11), PR (7), SD (2); } \\
\text { CIK cell treatment significantly enhanced immune functions } \\
\text { and quality of life }\end{array}$ \\
\hline Lu et al. [38] & I & B-cell NHL & 9 & autologous CIK cells & $\begin{array}{l}\text { CR (9); } \\
\text { the Karnofsky score was significantly higher }\end{array}$ \\
\hline Cai et al. [39] & $\mathrm{I}$ & CLL & 5 & autologous CIK cells $+\mathrm{TP} \alpha-1$ & CR (3), PR (2), SD (1) \\
\hline Yang et al. [40] & $\mathrm{I}$ & MM & 1 & autologous CIK cells & CR (1) without disease progression for 40 months \\
\hline Yang et al. [41] & I & AML & 5 & autologous CIK cells & No clinical response \\
\hline
\end{tabular}


Table 2. Cont

\begin{tabular}{|c|c|c|c|c|c|}
\hline Study Reference & Phase & Cancer Disease & Patients (n) & Therapy & Clinical Response \\
\hline Introna et al. [42] & I & $\begin{array}{c}\text { AML (4) } \\
\text { HD (3) } \\
\operatorname{MDS}(2) \\
\operatorname{ALL~(1)~} \\
\text { CML (1) }\end{array}$ & 11 & allogeneic CIK cells & $\begin{array}{l}\text { CR (3), PR (1), SD (1); } \\
\text { GVHD in four patients }\end{array}$ \\
\hline Laport et al. [43] & I & $\begin{array}{c}\text { B-cell NHL (5) } \\
\text { AML (3) } \\
\text { MM (3) } \\
\text { CLL (2) } \\
\text { ALL (2) } \\
\text { MDS (2) } \\
\text { HD (1) }\end{array}$ & 18 & allogeneic CIK cells & $\begin{array}{l}\text { CR (5) greater than } 1 \text { year; } \\
\text { GVHD in three patients. } \\
\text { The median overall survival was } 28 \text { months and median } \\
\text { event free survival was } 4 \text { months }\end{array}$ \\
\hline Introna et al. [44] & I & $\begin{array}{l}\text { AML (4) } \\
\operatorname{ALL}(1) \\
\end{array}$ & 5 & $\begin{array}{l}\text { cord-blood derived, } \\
\text { allogeneic CIK cells }\end{array}$ & PR (1) in one patient presenting with acute GVHD \\
\hline Linn et al. [45] & I & $\begin{array}{c}\text { AML (8) } \\
\text { ALL (3) } \\
\text { HD (3) } \\
\text { CML (1) } \\
\text { B-cell NHL (1) }\end{array}$ & 16 & allogeneic CIK cells & $\begin{array}{l}\text { Clinical response attributable to CIK cell infusion in five } \\
\text { patients; acute GVHD in three patients }\end{array}$ \\
\hline Jiang et al. [46] & $\mathrm{I}$ & Acute leukemia & 19 & $\begin{array}{l}\text { autologous CIK cells, } \\
\text { followed by chemotherapy }\end{array}$ & $\begin{array}{l}\text { CR rate was } 73.4 \% \text { in the CIK group versus } 27.3 \% \text { in the } \\
\text { control group }\end{array}$ \\
\hline Linn et al. [47] & $\mathrm{I} / \mathrm{II}$ & $\begin{array}{l}\text { AML (11) } \\
\text { CML (10) }\end{array}$ & 21 & autologous CIK cells & No clinical response \\
\hline Zhong et al. [48] & II & MM & 30 & $\begin{array}{l}\text { autologous DC-CIK cells }+ \\
\text { chemotherapy }\end{array}$ & $\begin{array}{l}\text { OS, quality of life and clinical indices were significantly } \\
\text { higher than in chemotherapy group }\end{array}$ \\
\hline
\end{tabular}

ALL: acute lymphoid leukemia; AML: acute myeloid leukemia; CIK: cytokine-induced killer; CLL: chronic lymphoid leukemia; CML: chronic myeloid leukemia; CR: complete remission; DC: dendritic cell; GVHD: graft-versus-host disease; HD: Hodgkin's disease; IL-2: interleukin-2; MDS: myelodysplastic syndrome; MM: multiple myeloma; NHL: non-Hodgkin's lymphoma; OS: overall survival; PR: partial remission; SD: stable disease; TP $\alpha-1$ : thymic peptide alpha-1. 


\section{Conclusions}

Major advances have been made in the field of adoptive immunotherapy, which has been considered a promising approach in taking advantage of the stimulated patient's immune system to recognize and eventually eliminate tumor cells. Among them, particularly CIK cells emphasize these natural abilities of the human immune system to destroy cancer cells and, thus, represent a unique immunotherapeutic approach, which enriched our therapeutic repertoire in the struggle against cancer. CIK cells exhibited significant antitumor activity in preclinical experiments and animal tumor models [2,3]. Their technically simple and inexpensive cultivation and their non-MHC-restricted cytotoxicity strongly promoted the transition from preclinical experiments to clinical application. Hence, it did not take very long until CIK cells were utilized in clinical trials facing a wide range of different tumor entities. Many of these trials reported on valuable results, as CIK cell therapy improved the quality of life and prolonged the patients' survival [5-7,30].

Here, in the context of hematological malignancies, we found corroborative evidence for the assumption that CIK cell immunotherapy benefits the patients in terms of recurrence prevention, improved quality of life and prolonged progression-free survival. Considerable antitumor effects were observed in various hematological malignancies, and most interestingly, side reactions were little or even absent.

The vast majority of patients that received autologous CIK cells experienced an improved disease state accompanied by an improved QOL and general presentation, even in advanced disease stages.

Of 123 patients, five patients achieved SD, 18 patients achieved PR and even 41 patients achieved CR; a proportion of 52\% achieved an improved disease stage with an overall response rate (ORR) of $48 \%$. In many cases, immunological parameters improved, tumor markers decreased and inflammation frequency was less than before CIK cell therapy. Despite these promising numbers, however, there were some studies suggesting that CIK cell therapy might not have a substantial impact on the course of hematological neoplasms. Especially, AML patients were shown to benefit least. The authors of the respective studies explained that either improper timing of the infusions or an insufficient quantity of CIK cells might have hindered more positive results [41,47]. Besides these factors, Linn et al. [47] describe the lack in $\mathrm{CD} 62 \mathrm{~L}$ and $\mathrm{CD} 27$ expression of the $\mathrm{CD} 3{ }^{+} \mathrm{CD} 56^{+}$subset, which is critical for lymphoid homing properties and anti-tumor immunity, as another imaginable reason for the reduced long-term efficacy of CIK cells [47].

Most interestingly, CIK cell therapy was not associated with any severe adverse effects, and more frequent side effects were mild, well tolerated by the patients and easy to control. However, approximately one quarter of the whole patient collective, including allogeneic settings, developed mild fevers, which eventually resolved after $24 \mathrm{~h}$ or could be treated with anti-inflammatory treatment. Other rather rare adverse reactions were also mild and easily treatable.

Apart from the use of CIK cells in the autologous treatment line, the non-MHC-restricted cytotoxic profile and reduced alloreactivity renders them attractive for the application across major HLA barriers, especially after allogeneic HSCT. As in autologous studies, the four clinical studies utilizing allogeneic CIK cells could prove the feasibility and safety of CIK cell therapy, since adverse reactions were equally frequent and mild. The efficiency was less favorable, but also showed initial encouraging results. In this regard, the major emphasis of these trials should not merely be placed on the CIK cell potency, but on the observation that allogeneic CIK cells caused only little toxicity, particularly 
GVHD. Only ten of 50 patients developed GVHD, in most cases, concomitantly with a clinical response [42-45]. Of note, most of these 50 patients received DLI prior to CIK cell infusions, but showed no sufficient response. This underlines the preclinical observations that the use of CIK cells as an updated form of DLI might be superior in terms of reduced alloreactivity and disease control. However, up to now, the reliable clinical use of allogeneic CIK cells has been limited to combination therapies with standard therapeutic regimens and should be preferred in more indolent diseases rather than in acute leukemia.

The described clinical studies predominantly suggest a superiority of CIK cell therapy as a second-line treatment along or after standard therapeutic procedures. In fact, this assumption is probably due to the currently applied inclusion criteria and safety concerns. Nevertheless, building upon the great safety profile and the relatively harmless extraction of CIK cells, this interesting therapeutic approach could also benefit the patients as a first-line treatment modality when combined with common therapeutic strategies, especially in the autologous form. However, substantial conclusions on the potential efficiency and on the question to what extent CIK cell therapy might influence the survival durations cannot be drawn at the moment. It is actually not difficult to find an explanation for this deadlocked situation, since there exists a vast heterogeneity in terms of study design, numbers of infused CIK cells, different proportions of CIK cell phenotypes within the infusions and outcome assessment. Moreover, the proper timing of the infusions seems to be critical, as well.

To face these disparities and to gradually homogenize future trials, we decided to found the International Registry on CIK cells (IRCC) in 2010. Our primary aim is providing standard instruments for the design and the outcome assessment of future trials, but also data collection and subsequent analysis to present the latest state of CIK cell efficacy and to broaden the acceptance and interest in this promising treatment approach [4,5].

Ongoing research efforts are decisive to address these open questions. The most crucial issue will be the development of superior treatment protocols. Most interesting in this regard appears the reduced alloreactivity of CIK cells by the depletion of $\mathrm{CD}^{+}{ }^{+} \mathrm{CD} 56^{-}$cells. Taking appropriate measures to deplete these cells within the heterogeneous amplification product could possibly contribute to even safer CIK cells in allogeneic treatment lines. Especially innovations in the generation of CIK cells by applying other cytokines than IL-2 or cytokine gene-transfection might not only accelerate the propagation of CIK cells, but also improve their in vivo cytotoxicity. Another valuable approach is the co-cultivation with antigen-presenting DCs, as their interaction renders CIK cells more aggressive and speeds up the expansion of the desired $\mathrm{CD} 3{ }^{+} \mathrm{CD} 56^{+}$subset. Hence, the implementation of the DC-CIK strategy, as well as the selection of varying cytokines seems tempting. It is regrettable that, except for DC-CIK, currently, none of the abovementioned improvement strategies have found a route to clinical application for the treatment of hematological neoplasms. However, larger scaled clinical trials covering these new strategies are indispensable and will hopefully disclose the potential of CIK cells in combination with further established therapies. In conclusion, much effort has been made in recent years to optimize the efficacy of CIK cells and to realize the translation of CIK cells into clinical practice, where they proved safe and efficient. Plenty of innovative ideas will promote the progression in this fascinating field, and CIK cells might, therefore, play an outstanding role in the treatment of hematological malignancies in the future. 


\section{Author Contributions}

F.C. Schmeel and L.C. Schmeel contributed equally to this work as joint first authors.

F.C. Schmeel and L.C. Schmeel conceived of the project, did all analyses and wrote the paper. S.-M. Gast contributed patient data and reviewed and edited the paper. I.G.H. Schmidt-Wolf conceived of the project, contributed patient data and reviewed and edited the paper.

\section{Conflicts of Interest}

The authors declare no conflict of interest.

\section{References}

1. Balducci, L.; Yates, J. General guidelines for the management of older patients with cancer. Oncology 2000, 14, 221-227.

2. Schmidt-Wolf, I.G.; Negrin, R.S.; Kiem, H.P.; Blume, K.G.; Weissman, I.L. Use of a SCID mouse/human lymphoma model to evaluate cytokine-induced killer cells with potent antitumor cell activity. J. Exp. Med. 1991, 174, 139-149.

3. Lu, P.H.; Negrin, R.S. A novel population of expanded human CD3+CD56+ cells derived from $\mathrm{T}$ cells with potent in vivo antitumor activity in mice with severe combined immunodeficiency. J. Immunol. 1994, 153, 1687-1696.

4. Schmeel, L.C.; Schmeel, F.C.; Coch, C.; Schmidt-Wolf, I.G. 25 years of CIK cells in cancer immunotherapy: Report of the International Registry on CIK cells (IRCC). Unpublished work, 2014.

5. Hontscha, C.; Borck, Y.; Zhou, H.; Messmer, D.; Schmidt-Wolf, I.G. Clinical trials on CIK cells: First report of the international registry on CIK cells (IRCC). J. Cancer Res. Clin. Oncol. 2011, 137, 305-310.

6. Jäkel, C.E.; Schmidt-Wolf, I.G. An update on new adoptive immunotherapy strategies for solid tumors with cytokine-induced killer cells. Expert Opin. Biol. Ther. 2014, 147, 905-916.

7. Jäkel, C.E.; Vogt, A.; Gonzalez-Carmona, M.A.; Schmidt-Wolf, I.G. Clinical studies applying cytokine-induced killer cells for the treatment of gastrointestinal tumors. J. Immunol. Res. 2014, 897214, doi:10.1155/2014/897214.

8. Von Roenn, J.; Harris, J.E.; Braun, D.P. Suppressor cell function in solid tumor cancer patients. J. Clin. Oncol. 1987, 5, 150-159.

9. Schmidt-Wolf, I.G.; Lefterova, P.; Johnston, V.; Scheffold, C.; Csipai, M.; Mehta, B.A.; Tsuruo, T.; Huhn, D.; Negrin, R.S. Sensitivity of multidrug-resistant tumor cell lines to immunologic effector cells. Cell. Immunol. 1996, 169, 85-90.

10. Schmidt-Wolf, I.G.; Finke, S.; Trojaneck, B.; Denkena, A.; Lefterova, P.; Schwella, N.; Heuft, H.G.; Prange, G.; Korte, M.; Takeya, M.; et al. Phase I clinical study applying autologous immunological effector cells transfected with the interleukin-2 gene in patients with metastatic renal cancer, colorectal cancer and lymphoma. Br. J. Cancer 1999, 81, 1009-1016.

11. Schmidt-Wolf, I.G.; Lefterova, P.; Mehta, B.A.; Fernandez, L.P.; Huhn, D.; Blume, K.G.; Weissman, I.L.; Negrin, R.S. Phenotypic characterization and identification of effector cells involved in tumor cell recognition of cytokine-induced killer cells. Exp. Hematol. 1993, 21, 1673-1679. 
12. Sangiolo, D.; Martinuzzi, E.; Todorovic, M.; Vitaggio, K.; Vallario, A.; Jordaney, N.; Carnevale-Schianca, F.; Capaldi, A.; Geuna, M.; Casorzo, L.; et al. Alloreactivity and anti-tumor activity segregate within two distinct subsets of cytokine-induced killer (CIK) cells: Implications for their infusion across major HLA barriers. Int. Immunol. 2008, 20, 841-848.

13. Verneris, M.R.; Karami, M.; Baker, J.; Jayaswal, A.; Negrin, R.S. Role of NKG2D signalling in the cytotoxicity of activated and expanded CD8+ T cells. Blood 2004, 103, 3065-3072.

14. Groh, V.; Rhinehart, R.; Secrist, H.; Bauer, S.; Grabstein, K.H.; Spies, T. Broad tumor-associated expression and recognition by tumor-derived $\gamma \delta \mathrm{T}$ cells of MICA and MICB. Proc. Natl. Acad. Sci. USA 1999, 96, 6879-6884

15. Salih, H.R.; Antropius, H.; Gieseke, F.; Lutz, S.Z.; Kanz, L.; Rammensee, H.G.; Steinle, A. Functional expression and release of ligands for the activating immunoreceptor NKG2D in leukemia. Blood 2003, 102, 1389-1396.

16. Pende, D.; Rivera, P.; Marcenaro, S.; Chang, C.C.; Biassoni, R.; Conte, R.; Kubin, M.; Cosman, D.; Ferrone, S.; Moretta, L.; et al. Major histocompatibility complex class I-related chain A and UL16-binding protein expression on tumor cell lines of different histotypes: Analysis of tumor susceptibility to NKG2D-dependent natural killer cell cytotoxicity. Cancer Res. 2002, 62, 6178-6186.

17. Pievani, A.; Borleri, G.; Pende, D.; Moretta, L.; Rambaldi, A.; Golay, J.; Introna, M. Dual-functional capability of CD3+CD56+ CIK cells, a T-cell subset that acquires NK function and retains TCR-mediated specific cytotoxicity. Blood 2011, 118, 3301-3310.

18. Shablak, A.; Hawkins, R.E.; Rothwell, D.G.; Elkord, E. T cell-based immunotherapy of metastatic renal cell carcinoma: Modest success and future perspective. Clin. Cancer Res. 2009, 15, 6503-6510.

19. Li, H.; Yu, J.P.; Cao, S.; Wei, F.; Zhang, P.; An, X.M.; Huang, Z.T.; Ren, X.B. CD4+CD25+ regulatory $\mathrm{T}$ cells decreased the antitumor activity of cytokine-induced killer (CIK) cells of lung cancer patients. J. Clin. Immunol. 2007, 27, 317-326.

20. Lin, G.; Wang, J.; Lao, X.; Wang, J.; Li, L.; Li, S.; Zhang, J.; Dong, Y.; Chang, A.E.; Li, Q.; et al. Interleukin-6 inhibits regulatory $\mathrm{T}$ cells and improves the proliferation and cytotoxic activity of cytokine-induced killer cells. J. Immunother. 2012, 35, 337-343.

21. Heninger, A.K.; Theil, A.; Wilhelm, C.; Petzold, C.; Huebel, N.; Kretschmer, K.; Bonifacio, E.; Monti, P. IL-7 abrogates suppressive activity of human CD4+CD25+FOXP3+ regulatory T cells and allows expansion of alloreactive and autoreactive T cells. J. Immunol. 2012, 189, 5649-5658.

22. Finke, S.; Trojaneck, B.; Lefterova, P.; Csipai, M.; Wagner, E.; Kircheis, R.; Neubauer, A.; Huhn, D.; Wittig, B.; Schmidt-Wolf, I.G. Increase of proliferation rate and enhancement of antitumor cytotoxicity of expanded human CD3+ CD56+ immunologic effector cells by receptor-mediated transfection with the interleukin-7 gene. Gene Ther. 1998, 5, 31-39.

23. Rettinger, E.; Kuçi, S.; Naumann, I.; Becker, P.; Kreyenberg, H.; Anzaghe, M.; Willasch, A.; Koehl, U.; Bug, G.; Ruthardt, M.; et al. The cytotoxic potential of interleukin-15-stimulated cytokine-induced killer cells against leukemia cells. Cytotherapy 2012, 14, 91-103.

24. Tao, Q.; Chen, T.; Tao, L.; Wang, H.; Pan, Y.; Xiong, S.; Zhai, Z. IL-15 improves the cytotoxicity of cytokine-induced killer cells against leukemia cells by upregulating CD3+CD56+ cells and downregulating regulatory T cells as well as IL-35. J. Immunother. 2013, 36, 462-467. 
25. Zhao, N.; Zhao, M.F.; Rajbhandary, S.; Lu, W.Y.; Zhu, H.B.; Xiao, X.; Deng, Q.; Li, Y.M. Effects of humanized interleukin 21 on anti-leukemic activity of cytokine induced killer cells and the mechanism. Zhonghua Xue Ye Xue Za Zhi 2012, 33, 823-828.

26. Schmidt, J.; Eisold, S.; Büchler, M.W.; Märten, A. Dendritic cells reduce number and function of $\mathrm{CD} 4+\mathrm{CD} 25+$ cells in cytokine-induced killer cells derived from patients with pancreatic carcinoma. Cancer Immunol. Immunother. 2004, 53, 1018-1026.

27. Märten, A.; Ziske, C.; Schöttker, B.; Renoth, S.; Weineck, S.; Buttgereit, P.; Schakowski, F.; von Rücker, A.; Sauerbruch, T.; Schmidt-Wolf, I.G. Interactions between dendritic cells and cytokine-induced killer cells lead to an activation of both populations. J. Immunother. 2001, 24, 502-510.

28. Li, H.; Ren, X.B.; Zhang, P.; An, X.M.; Liu, H.; Hao, X.S. Dendritic cells reduce the number and function of CD4+CD25+ cells in cytokine-induced killer cells. Zhonghua Yi Xue Za Zhi 2005, 85, 3134-3138.

29. Li, Y.; Huang, S.L.; Zhang, X.C.; Fang, J.P.; Wu, Y.F.; Wei, J.; Huang, W.G.; Zhou, D.H.; Huang, K.; Lin, Y.C. The cytotoxicity of CIK/NK cells stimulated by K562-DC fusion vaccines in NOD/SCID mice model for human erythroleukemia (in Chinese). Zhonghua Xue Ye Xue Za Zhi 2008, 29, 39-43.

30. Thanendrarajan, S.; Nowak, M.; Abken, H.; Schmidt-Wolf, I.G. Combining cytokine-induced killer cells with vaccination in cancer immunotherapy: More than one plus one? Leuk. Res. 2011, 35, 1136-1142.

31. Verneris, M.R.; Ito, M.; Baker, J.; Arshi, A.; Negrin, R.S.; Shizuru, J.A. Engineering hematopoietic grafts: Purified allogeneic hematopoietic stem cells plus expanded CD8+ NK-T cells in the treatment of lymphoma. Biol. Blood Marrow Transplant. 2001, 7, 532-542.

32. Baker, J.; Verneris, M.R.; Ito, M.; Shizuru, J.A.; Negrin, R.S. Expansion of cytolytic CD8(+) natural killer T cells with limited capacity for graft-versus-host disease induction due to interferon gamma production. Blood 2001, 97, 2923-2931.

33. Leemhuis, T.; Wells, S.; Scheffold, C.; Edinger, M.; Negrin, R.S. A phase I trial of autologous cytokine-induced killer cells for the treatment of relapsed Hodgkin disease and non-Hodgkin lymphoma. Biol. Blood Marrow Transplant. 2005, 11, 181-187.

34. Olioso, P.; Giancola, R.; di Riti, M.; Contento, A.; Accorsi, P.; Iacone, A. Immunotherapy with cytokine induced killer cells in solid and hematopoietic tumours: A pilot clinical trial. Hematol. Oncol. 2009, 27, 130-139.

35. Yang, B.; Lu, X.C.; Zhu, H.L.; Han, W.D.; Wang, Y.; Fan, H.; Li, S.X.; Liu, Y.; Dai, H.R.; Yao, S.Q. Clinical study of autologous cytokine induced killer cells combined with IL-2 for therapy of elderly patients with B-cell malignant lymphoma (in Chinese). Zhongguo Shi Yan Xue Ye Xue Za Zhi 2010, 18, 1244-1249.

36. Liu, Y.; Bao, E.N.; Yang, B.; Lu, X.C.; Zhu, H.L.; Han, W.D.; Wang, Y.; Dai, H.R.; Yao, S.Q. Clinical study of autologous cytokine induced killer cell infusion treating for elderly patients with myelodysplastic syndrome (in Chinese). Zhongguo Shi Yan Xue Ye Xue Za Zhi 2011, 19, 787-792.

37. Yang, B.; Lu, X.C.; Yu, R.L.; Chi, X.H.; Liu, Y.; Wang, Y.; Dai, H.R.; Zhu, H.L.; Cai, L.L.; Han, W.D. Repeated transfusions of autologous cytokine-induced killer cells for treatment of haematological malignancies in elderly patients: A pilot clinical trial. Hematol. Oncol. 2012, 30, 115-122.

38. Lu, X.C.; Yang, B.; Yu, R.L.; Chi, X.H.; Tuo, S.; Tuo, C.W.; Zhu, H.L.; Wang, Y.; Jiang, C.G.; $\mathrm{Fu}, \mathrm{X} . \mathrm{B}$; et al. Clinical study of autologous cytokine-induced killer cells for the treatment of elderly patients with diffuse large B-cell lymphoma. Cell Biochem. Biophys. 2012, 62, 257-265. 
39. Cai, L.L.; Yang, Y.; Yang, B.; Zhu, H.L.; Lu, X.C.; Zhang, W.Y.; Yu, R.L.; Chi, X.H.; Wang, Y.; Dai, H.R.; et al. Short-term curative efficacy of autologous cytokine induced killer cells combined with low-dose IL-2 regimen containing immune enhancement by thymic peptide in elderly patients with B-cell chronic lymphocytic leukemia (in Chinese). Zhongguo Shi Yan Xue Ye Xue Za Zhi 2012, 20, 564-570.

40. Yang, B.; Wang, J.; Cai, L.L.; Zhu, H.L.; Yu, R.L.; Chi, X.H.; Lu, X.C. Treatment of multiple solitary plasmacytomas with cytokine-induced killer cells. Cytotherapy 2014, 16, 278-284.

41. Yang, Y.; Yang, B.; Cai, L.L.; Ran, H.H.; Yu, R.L.; Chi, X.H.; Zhu, H.L.; Li, S.X.; Liu, Y.; Wang, Y.; et al. Clinical study of autologous cytokine induced killer cells combined with chemotherapy for elderly patients with acute myeloid leukemia (in Chinese). Zhongguo Shi Yan Xие Ye Xue Za Zhi 2014, 22, 58-63.

42. Introna, M.; Borleri, G.; Conti, E.; Franceschetti, M.; Barbui, A.M.; Broady, R.; Dander, E.; Gaipa, G.; D’Amico, G.; Biagi, E.; et al. Repeated infusions of donor-derived cytokine-induced killer cells in patients relapsing after allogeneic stem cell transplantation: A phase I study. Haematologica 2007, 92, 952-959.

43. Laport, G.G.; Sheehan, K.; Baker, J.; Armstrong, R.; Wong, R.M.; Lowsky, R.; Johnston, L.J.; Shizuru, J.A.; Miklos, D.; Arai, S.; et al. Adoptive immunotherapy with cytokine-induced killer cells for patients with relapsed hematologic malignancies after allogeneic hematopoietic cell transplantation. Biol. Blood Marrow Transplant. 2011, 17, 1679-1687.

44. Introna, M.; Pievani, A.; Borleri, G.; Capelli, C.; Algarotti, A.; Micò, C.; Grassi, A.; Oldani, E.; Golay, J.; Rambaldi, A. Feasibility and safety of adoptive immunotherapy with CIK cells after cord blood transplantation. Biol. Blood Marrow Transplant. 2010, 16, 1603-1607.

45. Linn, Y.C.; Niam, M.; Chu, S.; Choong, A.; Yong, H.X.; Heng, K.K.; Hwang, W.; Loh, Y.; Goh, Y.T.; Suck, G.; et al. The anti-tumour activity of allogeneic cytokine-induced killer cells in patients who relapse after allogeneic transplant for haematological malignancies. Bone Marrow Transplant. 2012, 47, 957-966.

46. Jiang, H.; Liu, K.Y.; Tong, C.R.; Jiang, B.; Lu, D.P. The efficacy of chemotherapy in combination with auto-cytokine-induced killer cells in acute leukemia (in Chinese). Zhonghua Nei Ke Za Zhi 2005, 44, 198-201.

47. Linn, Y.C.; Yong, H.X.; Niam, M.; Lim, T.J.; Chu, S.; Choong, A.; Chuah, C.; Goh, Y.T.; Hwang, W.; Loh, Y.; et al. A phase I/II clinical trial of autologous cytokine-induced killer cells as adjuvant immunotherapy for acute and chronic myeloid leukemia in clinical remission. Cytotherapy 2012, 14, 851-859.

48. Zhong, G.C.; Yan, B.; Sun, Y.; Zhang, X.Y.; Chen, J.; Su, Y.; Sun, H.P.; Zhu, B. Clinical efficacy of immunotherapy of dendritic cell and cytokine-induced killer cell combined with chemotherapy for treatment of multiple myeloma (in Chinese). Zhonghua Xue Ye Xue Za Zhi 2012, 33, 1000-1003.

(C) 2014 by the authors; licensee MDPI, Basel, Switzerland. This article is an open access article distributed under the terms and conditions of the Creative Commons Attribution license (http://creativecommons.org/licenses/by/3.0/). 